\title{
Female psychiatrists' career development after flexible training
}

\section{AIMS AND METHOD}

The project gathered data from a cohort of 300 flexibly trained female consultants in psychiatry in order to understand how their careers had progressed since the completion of their training. A postal questionnaire was used to gather this information.

\author{
RESULTS \\ These consultants were generally \\ satisfied with their training, and \\ were succeeding in pursuing their \\ careers. Flexible training was \\ developed to enable people with \\ family commitments to train in \\ psychiatry, and this is what it is being \\ used for.
}

\author{
CLINICAL IMPLICATIONS \\ Flexible training is an important \\ avenue for an increasing number of \\ psychiatrists to continue in their \\ profession. With the current shortfall \\ in consultant numbers, flexible \\ training should be maintained and \\ developed, and should be seen as a \\ useful route to a consultant position.
}

Formal flexible training first became available in 1969, and was specifically aimed at women with domestic commitments. Except for some posts in Oxford, the scheme was not greatly used until 1979, when there was a focusing on senior registrar training, with a second boost in 1991 with the introduction of a new scheme for career registrars. Demand for flexible training posts is growing, with a reported increase of 30\% across grades and specialties (Goldberg, 1997). It has been suggested that, nationally, $14 \%$ of psychiatrists train flexibly, although the uptake varies regionally between 3.5\% and 26\% (NHS Management Executive, 1993). More recent evidence suggests this figure is an underestimate: in a survey of consultant psychiatrists over 50 years of age, $16 \%$ had trained flexibly, and of these, 76\% were women (Mears et al, 2004). Today, it is likely that a significantly greater proportion of female consultant psychiatrists have trained flexibly.

This project builds on a survey carried out in the Thames region (Etchegoyen et al, 2001), which found that part-time training for women in this region was largely considered satisfactory, although not without difficulties. The national study described here extends the College Research Unit's existing workforce planning research.

\section{Method}

The questionnaire used in the Thames region study (Etchegoyen et al, 2001) was adapted for national use. The questions covered demographics, training, quality of subsequent posts, obstacles encountered and reasons behind career choices. Throughout the questionnaire, an anchored five-point Likert scale was used to yield useable data. The anchor points were 1 for no influence/not at all, 5 very influential/a great deal.

As no central record of flexible training exists, a list of all practising female consultants in the UK $(n=1689)$ was obtained from the registrations department of the Royal College of Psychiatrists. All individuals on the list were sent the questionnaire and asked to complete and return it if they had trained flexibly, and to return only the front page if they had not. Analyses were carried out on the data collected using the Statistical Package for the Social Sciences (SPSS, version 11.5).

\section{Results}

Three hundred useable questionnaires were returned, giving an adjusted response rate of $47.3 \%$ (taking account of non-flexibly trained respondents).

\section{Demographics and training}

Overwhelmingly, family commitments were reported as the key factor in the decision to train flexibly. Figure 1 shows the mean scores for each factor, using the fivepoint scale described above. Respondents were satisfied that their training had equipped them for the responsibilities they found after accreditation (mean score 4.4, s.d. 0.86), and that flexible training had enabled them to obtain the job of their choice (mean 4.2, s.d. 1.10) and had not hindered their clinical progress (mean 1.5, s.d. 0.96). However, respondents thought that flexible training had had a slightly negative influence upon academic progress (mean 2.4, s.d. 1.47).

\section{First post after accreditation}

The great majority of the sample (95\%) obtained a substantive post in psychiatry after accreditation, and for almost all (94\%) this was at consultant level. Of those responding, 43\% moved into full-time posts ( $n=127)$, a majority $(53 \%, n=155)$ worked in part-time posts, $4 \%$ in job shares; $83 \%(n=248)$ reported obtaining their first choice of working pattern (although for those in full-time posts, this figure drops to $73 \%$ ), with family commitments identified as the most important factor influencing that choice (mean 4.3, s.d. 1.24). The average number of sessions worked in the first job for part-timers was 7.0 (s.d. 1.8) and for all respondents it was 8.6 (s.d. 2.4). Respondents were generally satisfied with their first post (mean score 3.8, s.d. 1.12), and less than satisfied with support from management (mean 2.9, s.d. 1.16). 


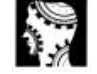

original papers

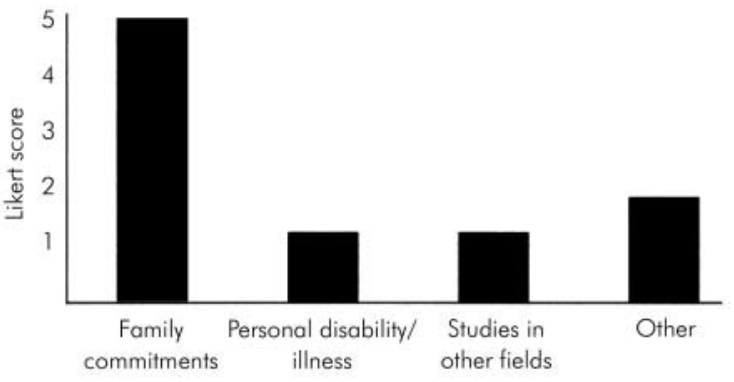

Fig. 1. Factors influencing the decision to train flexibly.

Respondents were asked to indicate if they had experienced any of a list of potential problems in their first post. These are shown, compared with problems encountered in subsequent posts, in Table 1.

\section{Subsequent posts}

Approximately a third $(n=101)$ of the sample had moved into a second post, with almost all (97\%) entering a consultant post, including $2 \%$ gaining an academic position. Of these, $54 \%$ were full-time posts, $43 \%$ parttime and 3\% job-sharing, with an average number of sessions worked of 9 (s.d. 2.6). The reasons for leaving the first post are listed in Table 2 . Respondents were generally satisfied with their second post (mean 3.8, s.d. 1.18), and with the support from management (mean 3.1, s.d. 1.35). Problems compared with those seen in the first substantive post are given in Table 1.

\section{Part-time $v$. full-time working}

Flexibly trained consultants working part-time were more positive than their flexibly trained full-time colleagues about their training, although differences were not statistically significant. Part-time workers scored a higher mean on how well they felt their training had equipped them for practice $(4.44$ v. $4.35, \mathrm{NS})$ and that it had helped them obtain their desired job (4.26 v. 4.15, NS). They were more satisfied with their first post (3.81 v. 3.79, NS), but scored slightly more highly on how far they felt flexible training had hindered their academic $(2.56$ v. 2.2, NS) and clinical (1.54 v. 1.42, NS) progress.

Table 1. Problems encountered in first and second substantive posts

\begin{tabular}{lrll}
\hline Problem & $\begin{array}{l}\text { Post 1 } \\
n(\%)\end{array}$ & $\begin{array}{l}\text { Post 2 } \\
n(\%)\end{array}$ & $\begin{array}{l}\text { Change } \\
(\%)\end{array}$ \\
\hline $\begin{array}{l}\text { Excessive workload } \\
\text { Problems with protected }\end{array}$ & $199(66)$ & $60(61)$ & -5 \\
$\quad$ study sessions per week & $152)$ & $48(49)$ & -3 \\
Lack of CPD time & $133(44)$ & $45(46)$ & +2 \\
Lack of administrative support & $91(30)$ & $31(32)$ & +2 \\
Lack of junior staff & $136(45)$ & $42(43)$ & -3 \\
Other & $74(25)$ & $28(29)$ & +3 \\
None of the above & $33(11)$ & $12(13)$ & +2 \\
\hline
\end{tabular}

CPD, continuing professional development.
Table 2. Reason for leaving first substantive post $(n=101)$

\begin{tabular}{lc} 
Reason & Response $n(\%)$ \\
\hline Obtained a better job & $37(37)$ \\
More children & $2(2)$ \\
Lack of job satisfaction & $23(23)$ \\
First job too stressful & $33(33)$ \\
Difficulties with management & $22(22)$ \\
Other & $56(56)$
\end{tabular}

Table 3. Problems encountered in full-time and part-time work

patterns

\begin{tabular}{lll} 
Problem encountered & $\begin{array}{l}\text { Full-time } \\
n(\%)\end{array}$ & $\begin{array}{l}\text { Part-time } \\
n(\%)\end{array}$ \\
\hline $\begin{array}{lll}\text { Lack of junior staff } \\
\text { Lack of administrative support }\end{array}$ & $55(43)$ & $76(49)$ \\
$\begin{array}{l}\text { Problems with protected study } \\
\text { sessions per week }\end{array}$ & $64(50)$ & $48(31)$ \\
$\begin{array}{l}\text { Lack of CPD time } \\
\text { Excessive workload }\end{array}$ & $51(40)$ & $76(49)$ \\
\hline
\end{tabular}

$\mathrm{CPD}$, continuing professional development.

Part-time consultants were found to be more likely to experience all of the problems listed in Table 3, apart from excessive workload.

\section{Discussion}

There are limitations to this study. With insufficient data to permit sampling of all flexibly trained psychiatrists nationally, the questionnaire form was sent to all female consultant psychiatrists. Although few men choose to train flexibly, representing only $3 \%$ of flexible trainees in one region (Etchegoyen et al, 2001), clearly our survey only addresses the experience of flexibly trained women. A retrospective sample was chosen, because the operational difficulties of identifying a national sample of those currently in flexible training were prohibitive. Finally, we have been unable to trace the potentially important group of flexibly trained individuals who did not progress to consultant status or who had left psychiatry altogether.

Flexible training is an increasingly important route for those who - for whatever reason - do not have enough time to take part in full-time training. Flexibly trained psychiatrists have been found to outperform their full-time colleagues in terms of how quickly they gain College membership (assessed by number of examination attempts), and also gain experience in other specialties prior to psychiatry (Herzberg \& Goldberg, 1999). This, coupled with a reported increase of $30 \%$ in demand for flexible training posts across specialties (Goldberg, 1997), shows that this is a crucial group for policy-makers to recognise and encourage.

The headlines from this study are positive: flexibly trained psychiatrists feel well-equipped for their work, and do not feel that their flexibly trained status has 
denied them opportunities to progress (in this, our study agrees with Etchegoyen et al, 2001).

Unsurprisingly and overwhelmingly, family reasons are primary in the decision to train flexibly. This is positive, since this route for training was originally introduced to meet the needs of people whose family commitments were preventing them from entering full-time training

After training, over three-quarters of the sample moved into their first choice of working pattern (equally divided between full-time and part-time, the choice again largely governed by family commitments). That for nearly a quarter of those in a full-time post this was not their first choice of working pattern indicates that more and better opportunities for flexible working at consultant level are needed. This first post was reported as largely satisfying, although problems were encountered and support from management was poor. However, these issues are shared by all consultant psychiatrists, and are not confined to the flexibly trained (Mears et al, 2002). A third of respondents had moved to another consultant post, largely for reasons centred around the job itself either the first post was unsatisfactory in some way, or a better opportunity presented itself.

Although the results are not statistically significant, a tendency emerges that consultants in part-time posts have a more positive image of their training, although they are more likely to feel it had hindered their academic career progress. Data also suggest (although again not with statistical significance) that part-time consultants are encountering problems more frequently than their full-time counterparts, with the notable exception of excessive workload. This might lead to a hypothesis that those in part-time posts tend to be more skilled at managing their time.

In summary, flexible training is being taken up by those whose family commitments are preventing them from training full-time, which is appropriate, since this is its primary purpose. Concerns that training flexibly might cause problems for those who use this route have been largely undermined by this study. Findings also suggest, however, that women who train flexibly believe that this route might hinder academic progression, and this may account, at least in part, for the underrepresentation of women in academic psychiatry (Killaspy et al, 2003). Flexibly trained consultants do face problems with their work, but these are mirrored by those faced by their nonflexibly trained peers.

\section{Declaration of interest}

The study was funded by the Department of Health as part of College Research Unit workforce planning research.

\section{References}

ETCHEGOYEN, A., STORMONT, F. \& GOLDBERG, I. (2001) Career success after flexible training in psychiatry. A survey of former flexible trainees in the Thames Region. British Journal of Hospital Medicine, 62, 355-357.

GOLDBERG, I. (1997) Flexible training in psychiatry. Psychiatric Bulletin, 21, 387-388.

HERZBERG, J. \& GOLDBERG, I. (1999) A survey of flexible trainees in psychiatry in the North and SouthThames Region. Psychiatric Bulletin, 23,616-618.

KILLASPY, H., JOHNSON, S., academic psychiatry in the United Kingdom. Psychiatric Bulletin, 27, 323-326.

MEARS, A., KENDALL, T., KATONA, C. et al (2002) Career Intentions of Psychiatric Trainees and Consultants. London: Department of Health.

MEARS, A., KENDALL, T., KATONA, C., et al (2004) Retirement intentions of older consultant psychiatrists. Psychiatric Bulletin, in press.

NHS MANAGEMENT EXECUTIVE (1993) FlexibleTraining: Report of the Joint LIVINGSTON, G., et al (2003) Women in

*Alex Mears Research Fellow, College Research Unit, 83 Victoria Street, London SW1H OHW (tel: 0207227 0835; e-mail: alex.mears@virgin.net), Alicia Etchegoyen Honorary Research Fellow, Fiona Stormont Honorary Research Fellow, Tim Kendall Deputy Director, College Research Unit, London, Cornelius Katona Dean, Royal College of Psychiatrists, London, Sarah Pajak ResearchWorker, College Research Unit, London 